\title{
CONCEPÇÕES PEDAGÓGICAS DE PROFESSORES/AS DA EDUCAÇÃO DE JOVENS E ADULTOS SOBRE A INTERDISCIPLINARIDADE
}

\author{
Maria Clarisse Vieira ${ }^{1}$ \\ Cristino Cesário Rocha²
}

\begin{abstract}
RESUMO
$\mathrm{O}$ artigo tem por objetivo identificar, compreender e analisar concepções de professores/as de diferentes disciplinas e áreas do conhecimento sobre a interdisciplinaridade e suas práticas, intenções e condições de ensinar interdisciplinarmente. Com base em Tonet (2013) e Freire (2015) realiza uma reflexão teórico-conceitual que lança luzes sobre práticas pedagógicas de professores/as que atuam na Educação de Jovens e Adultos. Tem como metodologia a abordagem qualitativa ancorada em Lüdke e André (2015). A interdisciplinaridade é vista pelos professores/as em duplo sentido: prático e teórico, e sua articulação pode ser feita com a contribuição de diversas instituições e movimentos sociais.

Palavras-chave: Concepções pedagógicas. Educação de Jovens e Adultos. Professores. Interdisciplinaridade.
\end{abstract}

\section{PEDAGOGICAL CONCEPTIONS OF TEACHERS OF EDUCATION OF YOUTH AND ADULTS ON INTERDISCIPLINARITY}

\section{ABSTRACT}

The aim of this study is to identify, understand and analyze the conceptions of teachers from different disciplines and areas of knowledge on the interdisciplinarity and its practices, intentions and conditions. Based on Tonet (2013) and Freire (2015) make a theoretical-conceptual reflection that throws light on pedagogical practices of teachers who work in the Education of Young and Adults. The research adopted a qualitative approach based in Lüdke and André (2015). The conclusion shows that interdisciplinarity can be studied by teachers in two directions: practical and theoretical and that articulation can be made with the contribution of various institutions and social movements.

Keywords: Pedagogical conceptions. Education of Young and Adults Interdisciplinarity. Teachers.

RECEBIDO EM: 21/2/1018

ACEITO EM: 26/6/2018

\footnotetext{
${ }^{1}$ Professora da Faculdade de Educação e do Programa de Pós-Graduação em Educação da Universidade de Brasília. Pedagoga com Mestrado em Educação pela Universidade Federal de Uberlândia (2000) e Doutorado em Educação pela Universidade Federal de Minas Gerais (2006). mclarissev@yahoo.com.br

${ }^{2}$ Professor de Filosofia e Sociologia da rede pública do Distrito Federal. Mestre em Educação pelo PPGE/UnB/FE e especialista em Administração da Educação; Culturas negras no Atlântico: História da África e Afro-brasileiros; Educação, Democracia e Gestão Escolar e em Educação na Diversidade e Cidadania com ênfase na Educação de Jovens e Adultos. cristino.arcanjo@gmail.com
} 
O homem tem relação com tudo o que conhece. Todas as coisas, sendo causadas e causantes, ajudadas e ajudantes, considero impossível conhecer as partes sem conhecer o todo; não mais que conhecer o todo sem conhecer particularmente as partes (PASCAL, 1995, p. 146).

Blaise Pascal nos convida a uma discussão que apreenda a pessoa humana como ser de relações. Sua concepção é inspiradora ao colocar-se diante da vida como totalidade que não tem o sentido de junção das partes. Conhecer por meio da relação, articulando o todo e as partes, dialeticamente, é o caminho para um fecundo processo de atuação interdisciplinar como movimento articulador do conhecimento, do ensinar e do aprender; da ação-reflexão e reflexão-ação com base ontológico-epistemológica e política, livre de uma postura isolada do/a professor/a ante sua disciplina.

Tratar da atuação e concepção docente em qualquer modalidade exige, e particularmente na Educação de Jovens e Adultos, entender que a escola pública brasileira atual está situada em um contexto de profundas transformações com crises e disputas ideológicas em todas as esferas. Sendo assim, concepções e práticas de professores/as tornam-se ainda mais exigentes, tanto no interior da escola quanto fora dela, em meio a um estado de coisas em andamento.

O mundo em mudança, cada vez mais complexo e globalizado com toda a sua atrocidade e barbárie, exige de professores/as e de profissionais da educação leituras e releituras críticas. Esse mundo demanda não apenas denúncia, mas também ações propositivas sobre a importância e urgência de uma atuação pedagógica globalizada e interdisciplinar como contraponto à globalização do capital, de modo a acompanhar tais mudanças, que devem ser vistas sob uma perspectiva sistêmica e crítica.

Pensar e agir, interdisciplinarmente, na esteira das grandes mudanças, não significa uma adequação passiva e acrítica. O que se pode fazer, em meio às mudanças que se processam em âmbitos mundial e local, é analisar de forma crítica e propor uma educação que possibilite uma visão do conjunto, dialeticamente. Nesse sentido, a presente pesquisa procura estabelecer uma discussão sobre as concepções de professores/ as sobre a interdisciplinaridade, tendo por base contribuições teórico-conceituais que dialogam com a perspectiva analítica.

O arcabouço metodológico tem ancoragem em algumas contribuições da pesquisa qualitativa ao avanço do conhecimento em educação e compreensão dos processos escolares, institucionais, culturais, etc. (LUDKE; ANDRÉ, 2015). A estrutura do artigo está dividida em três partes: na primeira parte discute-se a fragmentação capitalista e impacto nas práticas pedagógicas, a segunda analisa a educação como práxis problematizadora, com base em Freire, e, na terceira as concepções interdisciplinares de professores/as que atuam na EJA.

\section{FRAGMENTAÇÃO CAPITALISTA E IMPACTO NAS PRÁTICAS PEDAGÓGICAS}

Há diferentes contribuições sobre o conceito de interdisciplinaridade, assim como o de sua prática no âmbito da educação. Ivani Fazenda tem uma trajetória que não pode deixar de ser lembrada no tocante a essa discussão. A autora tem contribuído desde a década de 70, no Brasil, em conjunto com outros/as autores/as comprometidos/as com o ideário interdisciplinar como campo de estudo e de práticas pedagógicas. 
A década de 70, a título de exemplo, tem uma relevância no trato da interdisciplinaridade, considerada por Fazenda (2012) como um tempo de emergência de suas contribuições. As contribuições de Fazenda e outros autores sobre a interdisciplinaridade no contexto brasileiro tem sua raiz em movimentos sociais, estudantis emergentes da década de 60 na Europa, fato que deu um contorno político às discussões feitas no Brasil, de modo a assumir a interdisciplinaridade como um movimento que articularia o ser, o saber e a realidade humana com seu dinamismo.

A discussão aqui proposta parte do diálogo sobre interdisciplinaridade viabilizado por alguns estudos. Para estabelecer o diálogo que problematiza a interdisciplinaridade, traz-se ao debate contribuições de Tonet (2013) e Freire (2015), entre outros.

O percurso da ideia de interdisciplinaridade, reconhecendo sua limitação ante a complexidade humana num mundo em mudança, tem sua emergência e importância como quebra de uma lógica puramente formal e técnica do conhecimento e da própria vida na direção de uma postura humana e pedagógica pautadas na totalidade, como um aspecto constitutivo da vida em todas as suas esferas e implicações.

O surgimento da ideia de interdisciplinaridade vinculada à crítica ao sistema capitalista como prática perversa (fragmenta objetos e pessoas, massifica e objetiva o ser) é algo de suma importância para entender a necessária luta pela superação de relações desiguais em várias esferas da vida humana. Nesse sentido, ao se pretender uma prática interdisciplinar que parta de uma crítica da fragmentação da ciência e do conhecimento sem que haja uma crítica ao modo de produção da existência, pode-se esconder o real fator de esfacelamento político-social, econômico e epistemológico que incide sobre as práticas pedagógicas.

A interdisciplinaridade tem pontos comuns de emergência com a divisão da sociedade em termos econômicos (desigualdades) sociais, estruturais e culturais. Ela, fundamentalmente, em contexto de crise, é uma busca por soluções superativas e/ou amenizadoras de processos educacionais, dentro de estruturas econômicas produtoras de estratificação social, política, econômica, étnico-racial, de gênero, epistemológica, entre outras, e que reverbera em práticas pedagógicas fragmentadas e estandardizadas. É um pouco do que Capra (1982, p. 14) assegura ao afirmar que "a visão de mundo mecanicista da ciência cartesiano-newtoniana não pode ser mais aplicada em uma realidade que se transforma continuamente".

A interdisciplinaridade não está isolada nem descolada da divisão do trabalho social. É, portanto, moldada por princípios capitalistas. Ivo Tonet (2013) concebe esta nomenclatura a partir da divisão social do trabalho que produz outras divisões e fragmentações, inclusive nos processos pedagógicos. Neste contexto reflexivo, apresenta aportes significativos que possibilitam um entendimento das práticas pedagógicas, assim como da própria interdisciplinaridade influenciada por relações de produção.

Ao realizar a crítica necessária à compartimentação de saberes, cabe uma compreensão de seu processo que não se dá por pura vontade de professores/as e estudantes, na estreita relação do ensinar e do aprender, mas tem a ver com o modo como se processa a divisão social do trabalho. 
A fragmentação do saber tem sua origem na divisão social do trabalho surgida com a propriedade privada e, na sua forma específica moderna, na fragmentação do processo capitalista de produção da riqueza material e é funcional a sua reprodução. Não por acaso, esta forma de sociedade é que permite a exploração do capital sobre o trabalho e, portanto, a manutenção dos interesses da classe burguesa. Ao impedir uma visão de totalidade do processo social e ao gerar uma compreensão desse mesmo processo apenas em sua aparência, esta forma de saber contribui para reproduzir um tipo de sociedade de interesse da burguesia (TONET, 2013, p. 737).

Essa aproximação entre saber escolar fragmentado e divisão social do trabalho em contexto de propriedade privada, além de reconhecer a reprodução sistemática de modelo capitalista em sala de aula, sugere que não se pode culpabilizar professores/as e estudantes por um tipo de ensino fragmentado, mas de buscar compreender a dinâmica capitalista e encontrar saídas com uma atitude de corresponsabilidade, mas sem uma proposta moralizante.

Parece oportuno trazer à baila uma visão de Tonet que problematiza a interdisciplinaridade de forma mais crítica e intensa possível. Esse modo de ver não é visto como uma espécie de pessimismo, mas como uma provocação à forma como lidamos com o conhecimento, escola, educação, etc.:

Não há, pois, a menor possibilidade de superar a fragmentação do saber pela via puramente epistemológica e nem mesmo por nenhum esforço pedagógico ou comportamental. E mais ainda: quanto mais perdura esta forma de sociabilidade, mais se intensifica a fragmentação, pois isto é da lógica do capital e, portanto, mais forte se torna a mistificação do saber, independente de quantos esforços forem envidados para superá-la por via puramente epistemológica (TONET, 2013, p. 737).

Não há como negar que a lógica capitalista que fragmenta, divide, compartimentaliza saberes e a própria vida tenha impacto negativo em termos pedagógicos e humanos, mas não se pode também cair na inércia e no comodismo. A vida não é metafisicamente determinada como um muro sem saída, mas ontologicamente aberta, ao novo e ao poder- ser.

É fato que, em plano utópico, superar a sociedade de classes, dividida em seus vários aspectos, seria o ideal, o sonho que se alimenta a cada momento no seio da história humana. Esse nível utópico é proposto por Ivo Tonet ao tratar da aproximação entre saber e sociedade de classe:

Somente a constituição de um mundo que elimine a divisão social do trabalho e, portanto, a separação entre interesse particular e interesse geral, entre trabalho manual e trabalho intelectual, que suprima as classes com seus interesses antagônicos, vale dizer, um mundo que seja uma totalidade humana não cindida, somente neste mundo será possível superar, integralmente, a fragmentação do saber (2013, p. 737).

Esperar a superação total das diversas divisões produzidas em contexto capitalista para articular um desenho do ensinar e do aprender de forma interdisciplinar tem o mesmo teor de esperar o fim do capitalismo para desenhar uma ação socializadora e 
de ajuda aos que padecem de fome. O faminto não espera pela revolução para poder comer, beber, se divertir, se vestir, etc. Qualquer ação que se oponha ao sistema capitalista, por menor que seja, ajuda a não alimentá-lo em sua perversidade.

A longa experiência de diferentes civilizações traduz, em nossos dias, de modo particular na realidade brasileira, que o capitalismo se reestrutura e se fortalece. Como estrutura de dominação e exploração sobrevive disso e de sua capacidade de se reinventar ao longo dos tempos. Nesse contexto, a ação humana não pode ser prisioneira desse ideário. Há o que fazer em nível microrrelacional que se oponha ao modo de operar capitalista e Ivo Tonet aponta para um caminho possível:

Com isto, não queremos afirmar que não seja possível, hoje, produzir um conhecimento que não seja fragmentado. Pelo contrário, isto não só é possível como também necessário. Afinal, se um saber fragmentado é funcional à manutenção dos interesses da classe burguesa, um saber que tenha na categoria da totalidade a sua chave metodológica e que, pela articulação entre as categorias da essência e da aparência (de caráter histórico e social), permita a desmistificação da realidade social, é do interesse da classe proletária (2013, p. 737).

Produzir conhecimento não fragmentado hoje, em qualquer modalidade da educação, de modo especial na Educação Básica, requer um duplo sentido e uma dupla luta: a luta pela superação da divisão social do trabalho, em um plano mais amplo, e a superação de relações e mentalidades que dividem de um lado quem sabe e de outro quem não sabe; de um lado os que pensam e de outro os que fazem e assim por diante. Pela complexidade da superação de nível estrutural (divisão social do trabalho) há que agir de forma mais humanisticamente possível, atuando nas microrrelações de poder redefinindo paulatinamente modos de ser, pensar e agir, minando, por baixo, estruturas de poder dominantes.

Ainda a esse respeito, a fragmentação material produtiva é chave para compreender a necessária superação da divisão de saberes, e a partir disso, não correr o perigo da velha culpabilização de docentes por empreenderem um determinado tipo de ensino. Ivo Tonet deixa claro que o processo da produção material do e pelo trabalho condiciona o modo pelo qual se ensina e se aprende, entre outras dinâmicas pedagógicas e administrativas:

A superação da fragmentação no processo de produção da riqueza material e a superação da fragmentação no processo de produção do conhecimento são dois momentos articulados. Cada um tem uma especificidade própria, mas condicionam-se mutuamente nesta trajetória de construção de outra forma de sociabilidade. É preciso, contudo, acrescentar que, entre os dois, a fragmentação material é o momento fundamental. Sua eliminação é conditio sine qua non para pôr um fim efetivo à cisão no interior do saber (TONET, 2013, p. 739).

Este autor estabelece uma relação estreita entre formação, emancipação e compreensão da origem da fragmentação e de sua necessária desmistificação. Admite-se ser esse um dos caminhos que uma interdisciplinaridade possa perfazer sem a pretensão de ser redentora da educação: 
Uma formação, em geral, voltada para a emancipação humana, hoje, só pode significar uma contribuição para o engajamento na radical superação da sociedade capitalista e na construção de uma sociedade comunista. Por isso, uma atividade teórica que se pretenda emancipadora passa, necessariamente, pela apropriação de um saber que permita a compreensão desta sociedade como uma totalidade, até a sua raiz mais profunda, e que também possibilite compreender a origem, a natureza e a função social da fragmentação, desmistificando, ao mesmo tempo, a sua forma atual (TONET, 2013, p. 740).

Compreender essa sociedade capitalista, dentro dela, como agente do capital, parece desafiador, mas o caminho mostra-se sem volta: a luta permanente em várias frentes é o caminho de quem vive e respira, diuturnamente, diferentes formas de manifestação do capitalismo. Essa possível superação proposta por Tonet tem seu contorno pedagógico, mas também de classe, etnia/raça, de gênero, etc. A tomada de consciência é um bom começo no enfrentamento a diversas formas de opressão e dominação.

O percurso reflexivo entre e com os autores vai ocorrendo, cada um com seu modo de conceber, mas alinhado do ponto de vista crítico-analítico. Freire (2015) propõe uma discussão de interesse a essa temática e objeto de estudo com aspectos problematizantes.

Educação problematizadora, oposta à educação bancária, tem em Paulo Freire uma preocupação singular e que desafia nossa prática pedagógica na escola pública ainda arraigada do bancarismo. Este autor traz elementos significativos sobre o que se considera como interdisciplinaridade, traduzida como educação problematizadora e dialógica. $O$ enfoque de Freire intercambia com o conjunto dos autores já mencionados, pois, rigorosidade metódica, o caráter dialético e a divisão social do trabalho produtivo são e podem ser problematizados em determinado contexto de educação.

\section{EDUCAÇÃO COMO PRÁXIS PROBLEMATIZADORA: Contribuições de Freire Para a Interdisciplinaridade}

Compreender o processo de massificação e alienação da educação bancária é condição para se aproximar de uma perspectiva interdisciplinar, de forma que Freire (2015, p. 82) esclarece o que se entende por concepção bancária: "na concepção bancária, a educação é o ato de depositar, de transferir, de transmitir valores e conhecimentos".

Ter a lucidez de que a concepção e prática bancária não ajudam na superação da fragmentação e compartimentação dos saberes, e tampouco rompe com processos de dominação pessoal e social, pode conduzir a novos e elevados patamares de ação-reflexão. Na educação bancária reforça-se a dominação pessoa-pessoa, muito claramente na relação professor-estudante. Freire elenca aspectos da educação bancária que podem dificultar a superação da contradição educador-educando e outras questões importantes do processo educativo:

O educador é o que educa; os educandos, os que são educados; o educador é o que sabe; os educandos, os que não sabem; o educador é o que pensa; os educandos, os pensados; o educador é o que diz a palavra; os educandos, os que escutam docilmente; o educador é o que disciplina; os educandos, os disciplinados; o educador é o que opta e prescreve sua opção; os educandos, os que seguem a pres- 
crição; o educador é o que atua; os educandos, os que têm a ilusão de que atuam, na atuação do educador; o educador escolhe o conteúdo programático; os educandos, jamais ouvidos nesta escolha, se acomodam a ele; o educador identifica a autoridade do saber com sua autoridade funcional, que opõe antagonicamente à liberdade dos educandos; estes devem adaptar-se às determinações daquele; o educador, finalmente, é o sujeito do processo; os educandos, meros objetos (FREIRE, 2015, p. 82-83).

Essa plataforma de aspectos constitutivos da educação bancária, oposta a uma educação libertadora que promove a discussão e o aprendizado por meio da problematização, assume uma espécie de epistemologia do/a professor/a ancorada em um tipo de currículo e de concepção de pessoa, conhecimento, de ensino e de aprendizagem. Dito de outro modo: não há neutralidade na hora de propor e vivenciar um tipo de ensino com vistas a um tipo de aprendizagem.

Uma prática educativa bancária possui uma concepção de pessoa humana implícita ou explícita. A transformação do sujeito em objeto, sem condições básicas para exercer a sua situação de atuante, meramente receptor de mensagens e comandos, produz um ser submetido aos ditames dos interesses dominantes. Ela formata um sujeito pensado por outros, porque, nas palavras de Freire (2015, p. 83), "a educação bancária anula o poder criador dos educandos, estimula sua ingenuidade e satisfaz aos interesses dos opressores, pois para estes, o fundamento não é o desnudamento do mundo, a sua transformação".

Essa adaptação sem criticidade, típica de uma concepção e prática bancária, não tem interesse em alterar a realidade por meio de seu desvelamento e Freire $(2015, p$. 85) alerta para esse fato no âmbito da Educação de Jovens e Adultos: "na educação de adultos, por exemplo, não interessa, a esta visão bancária, propor aos educandos o desvelamento do mundo".

A dimensão interdisciplinar assume, em Freire (2015, p. 89), uma conotação problematizante na qual estudantes, professores e conhecimento são mediatizados pelo mundo assim explicitado: "o pensar do educador somente ganha autenticidade na autenticidade do pensar dos educandos, mediatizados ambos pela realidade, portanto, na intercomunicação".

Ao usar a palavra intercomunicação Freire expõe o entendimento de que conhecer é intercomunicar e não transmitir e transferir conhecimentos. A interdisciplinaridade poderá ser viável na medida em que haja intercomunicação e inter-relação entre as disciplinas, mais do que isso, entre professores, estudantes e o mundo em mudança.

Educação problematizadora em Freire (2015, p. 94) assume uma importância fundamental, de modo a estabelecer uma oposição radical à educação bancária: "ao contrário da educação bancária, a educação problematizadora, respondendo à essência do ser da consciência, que é sua intencionalidade, nega os comunicados e existencia a comunicação". 
Negar comunicados em uma relação mecanicista sujeito-objeto é condição para a possível relação dialógica construtivo-produtiva entre sujeito-sujeito. Uma atitude e prática interdisciplinar pautada na dialogicidade e na problematização criadoras e propulsoras de ensino e aprendizagens mais significativas pode ser um dos caminhos que levam a uma educação que altera determinada realidade.

Educação problematizadora é exigente, coloca em relevo a superação de tipos de contradições, ao que Freire (2015, p. 94-95) lembra a contradição entre educador-educando: "a educação problematizadora coloca, desde logo, a exigência da superação da contradição educador-educandos. Sem esta, não é possível a relação dialógica, indispensável à cognoscibilidade dos sujeitos cognoscentes, em torno do mesmo objeto cognoscível".

Superar a contradição educador-educando, quando o primeiro tende a estabelecer uma relação de dominação é, ao mesmo tempo, uma exigência ético-política e também um desafio pedagógico: trata-se de um aprendizado, de uma nova postura e de uma nova pedagogia baseada no reconhecimento de valores, crenças e conhecimentos presentes nos sujeitos educandos que também educam. Reconhecer acúmulo de saberes e ao mesmo tempo considerar limitações.

Contribuir com o despertar da percepção do sujeito sobre a sua coisificação e sua condição de sujeito inalienável em determinadas relações é uma função epistemológico-social da escola, dos/as professores/as e outras pessoas e instituições que acreditam na mudança por meio de um processo educativo crítico. Assim, Freire (2015, p. 100) deixa um entendimento de como se faz educação nesta lógica: "educação problematizadora se faz pelo esforço permanente, através do qual os homens vão se percebendo, criticamente, como estão sendo no mundo com e em que se acham".

Enquanto a prática bancária enfatiza, direta ou indiretamente, a percepção fatalista que estejam tendo os homens de sua situação, a prática problematizadora, ao contrário, propõe aos homens sua situação como problema. Propõe a eles sua situação como incidência de seu ato cognoscente, por meio do qual será possível a superação da percepção mágica ou ingênua que dela tenham (FREIRE, 2015, p. 104). O fatalismo é força que faz retroceder e estagnar. No modo fatalista de conceber o mundo, a realidade torna-se inexorável, intangível, impermeável. Essa construção mental fatalista da história humana não ajuda na superação das contradições trabalho-capital, oprimido-opressor, colonizado-colonizador, senhor-servo, educador-educando, etc.

A problematização, ao contrário, faz a crítica necessária e recoloca o lugar da pessoa humana na História como sujeito que se vê em outro patamar de consciência e de vida digna. A saída de uma postura disciplinar, unidirecional e unidimensional para uma postura interdisciplinar e intercomunicativa não pode ocorrer quando se assume uma concepção fatalista da História.

O diálogo é um ato indispensável no contexto de uma problematização que leve à mudança de si, do outro e do estado de coisas, entretanto não se trata de qualquer tipo de diálogo, como lembra Freire: 
O diálogo é uma exigência existencial. E, se ele é o encontro em que se solidarizam o refletir e o agir de seus sujeitos endereçados ao mundo a ser transformando e humanizado, não pode reduzir-se a um ato de depositar ideias de um sujeito no outro, nem tampouco tornar-se simples troca de ideias a serem consumidas pelos permutantes (FREIRE, 2015, p. 109).

Enfim, o diálogo é sempre uma condição da relação que se pretenda libertadora, o que, muito concretamente, se aproxima de um ideário de currículo, de ensino e de aprendizagem, de forma que Freire situa a dinâmica do encontro educador-educando na especificidade da escolha do conteúdo programático, mas que se estende a outras dinâmicas relacionais.

Dando continuidade a esta discussão, no item a seguir busca-se compreender e analisar concepções de professores/as de diferentes disciplinas e áreas do conhecimento da Educação de Jovens e Adultos sobre a interdisciplinaridade e suas práticas, intenções e condições de ensinar interdisciplinarmente. A ideia é estabelecer o cruzamento entre aspectos observados em sala de aula, as entrevistas e contribuições teórico-conceituais elucidativos dos autores anteriormente mencionados.

\section{CONCEPÇÕES DE PROFESSORES/AS SOBRE INTERDISCIPLINARIDADE}

As concepções e práticas pedagógicas de professores e professoras que atuam na Educação de Jovens e Adultos sobre a interdisciplinaridade possuem um valor singular no contexto da Educação Básica pública em todos os entes federados. Assim sendo, trazer à baila os entendimentos conceituais, as práticas, intenções, possibilidades e entraves sobre a interdisciplinaridade na Educação de Jovens e Adultos pode favorecer um maior engajamento qualitativo nessa modalidade.

Participaram deste estudo 19 professores/as do Centro de Ensino Fundamental na cidade de Samambaia-DF. A idade variou entre 36 e 55 anos. Todos eles são efetivos que atuam na Educação de Jovens e Adultos - Segundo Segmento. As entrevistas individuais foram realizadas com 13 professores/as no segundo semestre de 2017, quando nos apropriamos de 8 contribuições que adensam o texto e o contexto, constituindo-se em instrumentos para a geração e interpretação de dados. Esse material propiciou a reflexão e aproximação e/ou contraste com situações observadas em sala de aula, além de ter possibilitado a produção de concepções e compartilhamento de experiências interdisciplinares.

Para a seleção dos 8 professores, foram observados os processos de maior abertura e de participação na pesquisa desenvolvida entre fevereiro e setembro de 2017. Ademais, foram utilizados critérios que contemplam gênero, professor regente e professor readaptado, todos/as professores/as efetivos/as da Secretaria de Estado de Educação do Distrito Federal. Ao longo do artigo os professores/as participantes da pesquisa são identificados/as pelo nome conforme acordo de interesse.

O estudo tem por objetivo identificar, compreender e analisar concepções de professores/as de diferentes disciplinas e áreas do conhecimento da EJA sobre a interdisciplinaridade e suas práticas, intenções e condições de ensinar interdisciplinarmente. 
A interdisciplinaridade como atitude e ação de professores/as tem seu reconhecimento, porque defendida por quem está na linha de frente, estando no chão da sala de aula. Pode-se avaliar, entretanto, que a interdisciplinaridade remetida apenas ao campo da ação/atitude pode ter seu limite. Neste sentido, Tonet (2013) promove uma discussão sobre o possível equívoco desse modo de pensar, e alerta para o fato de que o desprezo do entendimento das bases materiais da fragmentação do conhecimento conduz ao equívoco de assumir o plano moralista, com ênfase em atitudes e práticas pedagógicas que integram distintos conhecimentos e disciplinas.

A interdisciplinaridade como ação do/a professor/a, muitas vezes pensada como atitude isolada de contextos mais amplos (instituições, estruturas, conjunturas), tem um modo de conceber importante em Francisco (Geografia). Para ele, "a interdisciplinaridade não é um problema da escola, nem do professor, mas da educação". Esse entendimento problematiza, em certa medida, a exigência que se faz ao professor/a de uma ação interdisciplinar descolada de suas condições reais de trabalho e mesmo das reais demandas dos estudantes. Problematiza também o fato de se entender o/a professor/a como o único provedor e portador de uma prática interdisciplinar, assumida, em muitos casos, como nas palavras de Francisco, "um trabalho a mais que pesa sobre o/a professor/a".

O entendimento que se coloca não é o de negação absoluta da interdisciplinaridade como uma atitude e prática, mas no que respeita ao que está por trás e para além da terminologia em si. A estreita relação que se estabelece entre ontologia e epistemologia não suprime o aspecto epistêmico, mas, pelo contrário, o integra dentro de uma produção do conhecimento com o alcance do ser social pensado e vivido integralmente. Daí porque Tonet (2013, p. 128) esclarece que "a crítica da interdisciplinaridade não é a crítica da interdisciplinaridade, mas a crítica do mundo que produz e necessita dessa forma de produção do saber".

Ao entender a interdisciplinaridade como interação dos conhecimentos, Aldaíres dá um passo à frente, principalmente quando acredita permitir um estudo mais abrangente, referindo-se ao que pode acontecer para além de sua disciplina e das demais. Esse modo de pensar aproxima-se do que a professora Cleci define como "interação entre as disciplinas" Ainda neste ponto, David acrescenta alguns elementos importantes, uma vez que, em sua concepção, apesar dos atropelos pessoais e institucionais, a interdisciplinaridade é atrelamento e entrelaçamento de distintas disciplinas:

Interdisciplinaridade é um trabalho que atrela português, matemática, ciência, etc. É entrelaçamento de disciplinas. O conhecimento é um só. Tenho uma boa visão do processo. Entrelaçar as disciplinas - o proveito é muito grande (Professor David Inglês/Português: entrevista em 9/9/2017).

Dois termos são usados por David para identificar o conceito de interdisciplinaridade: atrelar e entrelaçar. O primeiro pode ser entendido neste contexto como prender, ligar. O segundo como enlace entre duas ou mais coisas e/ou pessoas. Ambas, no modo de se expressar de David, são conexões ou relações com. 
Ao entender que o conhecimento é um só e que os vários níveis de conhecimento estão entrelaçados, unidos entre si, apesar de seus diferentes alcances no sentido de unidade e não de pensamento único, David recoloca a importância de religar a unidade do que foi quebrado. A esse respeito, Morin (2011) alerta para o fato da inadequação de saberes fragmentados em um mundo globalizado e com problemas que exigem outros modos de conceber, tanto o conhecimento quanto a realidade social:

Há inadequação cada vez mais ampla, profunda e grave entre os saberes separados, fragmentados, compartimentados entre as disciplinas, e, por outro lado, realidades ou problemas cada vez mais pluridisciplinares, transversais, multidimensionais, transnacionais, globais, planetários (MORIN, 2011, p. 13).

Essa inadequação, por sinal considerada grave, pode ser superada na medida do possível quando se pensa e repensa o que entendemos por conhecimento, educação, pessoa e sociedade. Saber qual tipo de conhecimento é necessário à Educação de Jovens e Adultos, assim como para qual tipo de sociedade (sociabilidade), põe em relevo o que ensinar e com qual metodologia. Considerar proveitoso o entrelaçamento entre disciplinas e conhecimentos aponta para a relevância da interdisciplinaridade concebida com esta particularidade, embora o conjunto da reflexividade tenha tomado o termo interdisciplinaridade de maneira problematizadora e com um extenso dimensionamento e redimensionamento.

As contribuições teórico-conceituais têm demonstrado que não basta ter a visão interdisciplinar, principalmente a que dispõe apenas de um instrumental epistemológico. É importante entender, na esteira de Morin (2011, p. 14), que "o retalhamento das disciplinas torna impossível apreender o que é tecido junto, isto é, o complexo".

A apreensão do que é tecido junto assume uma possiblidade no entendimento do professor Francisco, ao referir que "interdisciplinaridade é quando uma coisa está ligada à outra, quando não se consegue definir o que é Filosofia, Sociologia, Geografia e História". Essa concepção tem a sua praticidade no que, em observação, o professor tem revelado e na sua narrativa que trouxe à tona sua vivência interdisciplinar, quando assegurou atuação interdisciplinar entre Geografia, Sociologia, Filosofia e História no período em que atuava na Escola Técnica de Ceilândia-DF.

A apreensão do complexo, assim como a do ser social pensado e vivido em sua unidade e totalidade, que se exprime em profunda complexificação (TONET, 2013), não apenas favorece uma interdisciplinaridade mais coerente com as grandes mutações históricas e culturais, como situa e ressitua a perspectiva interdisciplinar em contexto dialético, em que o que é tecido junto desarticula o que foi feito de forma estandardizante.

De fato, apreender o complexo não é fácil, de modo que professora Karina (Português), em sua concepção de interdisciplinaridade, tem esse entendimento quando afirma que "interdisciplinaridade é estar dentro das disciplinas. Não tem como trabalhar só Português, tem que trabalhar todo mundo junto, mas não é fácil. A interdisciplinaridade ainda não foi contemplada em sua plenitude. É um trabalho difícil". A ênfase na dificuldade e complexidade de tecer junto revela que Karina e demais professores/as não entendem a interdisciplinaridade de maneira simplista nem como algo de fácil acesso. 
Em uma perspectiva também ampla e exigente, Morin (2011) interpela uma compreensão da globalidade social, política, econômica e epistemológica, entre outras, como articulação de dois níveis de prática, necessárias em nossa realidade local e mundial: o senso de solidariedade e responsabilidade:

O enfraquecimento de uma percepção global leva ao enfraquecimento do senso de responsabilidade - cada um tende a ser responsável apenas por sua tarefa especializada - bem como ao enfraquecimento da solidariedade - ninguém mais preserva seu elo orgânico com a cidade e seus concidadãos (2011, p. 18).

A solidariedade, tanto no âmbito das relações humanas mais gerais quanto na sua especificidade entre os conhecimentos disciplinares, tem sido mais difícil, porém não impermeável no interior das escolas, assim como nas diversas relações sociais fora dela. Ser responsável por si e pelo conjunto dos seres e coisas parece ter uma prática enfraquecida na medida em que nos sentimos impactados/as por um tipo de sociabilidade capitalista que hospedamos ao longo de nossas trajetórias no e com o mundo. Neste contexto não se pode, a partir de uma visão isolada, estigmatizar e/ou assumir uma postura taxativa de professores/as e outros agentes sociais no que toca ao fazer pedagógico.

Ao tratar do imprescindível senso de solidariedade e de responsabilidade (MORIN, 2011), atentos/as às grandes transformações locais e mundiais, é também fator importante no processo de apropriação e produção do conhecimento procurar vencer as barreiras disciplinares. A esse respeito, a contribuição do professor José Aldcésar (Educação Física) traz um entendimento elucidativo:

Interdisciplinaridade vem no sentido de junção de saberes diferentes, de possibilidades diferentes de trabalhar determinados temas, determinados conteúdos. Quando há interdisciplinaridade você consegue dar mais significado ao conteúdo, ao processo de ensino-aprendizagem e puxa muito a atenção do aluno. Apesar da importância da interdisciplinaridade, ainda há muita barreira e trabalhamos ainda em caixinhas, o que se trabalha em uma disciplina considera mais importante do que em outra. Ainda há muita barreira. $O$ conceito é perfeito se colocado em prática (Professor José Aldcésar - Ed. Física: entrevista em 17/8/2017).

José Aldcésar atribui a ideia de junção à interdisciplinaridade, além de atrelar e entrelaçar conhecimentos. Pelo teor e entendimento do professor, a junção não tem um sentido de justaposição, em que diferentes disciplinas se encontram sem estabelecer conexões significativas. Estar junto na condição de professor/a e no âmbito disciplinar é fato, não implica necessariamente discussão e atuação interdisciplinar.

A concepção de que a interdisciplinaridade dá significado ao conteúdo é ponto de alta relevância no ato de pensa-la e praticá-la, porque marca uma posição intencional da educação, de conhecimento que não esteja isolado de um contexto humano mais amplo. Considerar que o ensino e a aprendizagem ficam mais atraentes é sinal de que há resultado nesse modo de atuar pedagogicamente. Em outras narrativas, professores/ as dizem "dar certo" e que "alunos entendem as conexões entre as disciplinas", fato que imprime um caráter intencional ao ato de educar e que nas palavras de Pinto (1982, p. 49), essa intencionalidade pode atingir um grau de maior alcance quando há "mudança na condição humana do indivíduo que adquire saber, por isso a educação é substantiva, altera o ser do homem". 
Apesar da importância da interdisciplinaridade mencionada por José Aldcésar, fica claro em seu entendimento que há recorrência de barreiras disciplinares, o que ele chama de "caixinhas", em decorrência, segundo ele, da sensação de se sentir melhor do que o outro em seu domínio puramente disciplinar. Essa noção tem implicação mais geral: o próprio sistema educacional reforça essa mentalidade, quando atribui tempo desigual entre as disciplinas e maior importância às exatas, por exemplo.

Há uma interface no modo de conceber de José Aldcésar entre o que concebe por interdisciplinaridade e o que ele sente em nível pessoal, explicitamente no que considera ser limite de sua atuação. Observa ele: "minha formação no que tange à interdisciplinaridade ainda está na caixinha. $\mathrm{O}$ que aprendi está guardado na caixinha. $\mathrm{O}$ aprendizado que tive só aparece quando sou motivado, provocado".

Dizer que o conceito de interdisciplinaridade "é perfeito", mas que ganha maior importância em sentido prático tem um valor, mas somente quando essa prática não fica apenas no puramente epistemológico e de atuação pedagógica. É importante pensar na perspectiva de Tonet (2013), no sentido de promover a ação pedagógica de forma articulada: o ontológico, o ser social com suas múltiplas determinações e o epistêmico aberto a essas determinações.

Há que problematizar a ideia de "perfeição conceitual" proposta por José Aldcésar. No mundo da prática, o seu desenvolvimento histórico-cultural desafia qualquer noção de perfeição, inclusive no âmbito das práticas pedagógicas e das aprendizagens. O que se pode apreender é que a interdisciplinaridade, longe de ter um conceito e uma prática perfeitos, constitui-se, assim como a realidade humana, como um vasto campo de expressões de concepções e práticas possíveis, condicionadas e permeadas por uma multiplicidade de crenças, valores e adversidades.

Neste tópico ficou evidenciada a variedade de concepções interdisciplinares, muito próximas das vivências relatadas por professores e professoras. O professor Tarcísio oferece uma concepção que abre o caminho para a continuidade de nossa conversa: "Interdisciplinaridade para mim é união, unir o conhecimento. O conhecimento não é estanque. Essa é a ideia maior. Unir para que não fique estanque, para que cada um não fique dentro de sua casinha. Ao conversar, a coisa vai caminhando". É fato também que todos os teóricos fazem uma discussão importantíssima que qualifica, amplia e retroalimenta práticas e concepções interdisciplinares.

É dentro desse espírito, não estanque, fora das "caixinhas" (David) e livre das "casinhas" (Tarcísio) que vamos andando e conversando, por vezes praticando sem nos escondermos à sombra de um pragmatismo irrefletido e livres da sombra de uma reflexão estéril. O contexto de reflexividade dessa discussão teórico-vivencial permite adentrar em contexto mais amplo que impacta nas relações sociais e nas práticas pedagógicas.

\section{CONCLUSÕES INACABADAS}

Parte-se do pressuposto de que não há finalização absoluta nesta discussão por duas razões: primeiro porque não há como concluir o inacabado, segundo, porque, ao ser inacabado, pode-se buscar outros alcances de entendimento e de práticas interdisciplinares para além dessa terminologia. 
As várias narrativas (entrevistas), bem como as observações em sala de aula, revelaram que há experiências/vivências da interdisciplinaridade e que, ao mesmo tempo, os professores/as não a consideram algo fácil de entender nem de praticar. A humildade de se colocar ante uma terminologia, apesar de muitos terem momentos de estudos sobre o termo na universidade e na escola normal, permite afirmar que se pode assumir também a humildade disciplinar, no sentido de perceber os limites da visão unidimensional.

Ficou evidente que há diferentes formas de aproximar uma disciplina da outra e que, via de regra, foi proveitosa cada aproximação na medida em que o perfil dos professores e professoras tem um quê de compromisso coletivo com o que se propõem a fazer - projetos - constantes no Projeto Político-Pedagógico e realizados em termos práticos, de acordo com as condições internas da escola.

A gama de disciplinas explicitadas como possíveis no âmbito interdisciplinar tem uma conceitualização diversa, diante do que propõe-se a seguinte assertiva: o termo interdisciplinaridade emerge nas narrativas com uma polissemia que enriquece a discussão e a prática interdisciplinar, em que pese a necessidade de ampliar concepções e práticas. Os conceitos e termos mais comuns que emergiram nas narrativas foram: interdisciplinaridade como interação, algo difícil de apreender e praticar, uma postura do/a professor/a, prática, união, atrelamento, entrelaçamento, junção, interligação de saberes, complexidade, etc. Essas noções foram e seguem sendo importantes, e ganham explicação mais ampla segundo alguns autores que lançam luzes no texto e no contexto.

Sem as reflexões mais abrangentes, de nível socioeconômico e ontológico, ficaria mais difícil entender a prática interdisciplinar. E entendê-la, em sentido mais amplo, não inviabiliza sua possibilidade. Dizer que é complexa, de difícil apreensão e que é necessário superar a relação de dominação trabalho-capital não tem a ver com impermeabilidade, com fatalismo histórico e estagnação da ação-reflexão e vice-versa. Entender a complexidade global, sim. Estagnar, não.

Interdisciplinaridade não é um imperativo legal, não é um fim em si mesmo, não é solução para todos os males, mas o que pode ser? O conjunto das reflexões aqui feitas revela ser uma complexidade epistemológico-ontológico-pedagógica, uma possibilidade, um movimento articulador do conhecimento e das aprendizagens. Pode ser mais? Sim, no âmbito do devir humano.

Na ponta do trabalho pedagógico está o estudante que tem desejos, decisão, vontade, criatividade, sonhos, necessidades. Uma prática pedagógica, por menor que seja o seu nível de compreensão do que seja conhecimento e de como trabalhar, tem necessariamente impacto na vida tanto de quem ensina e aprende quanto na de quem aprende e ensina.

Nesta perspectiva, entende-se que, a partir do diálogo com os/as professores/as, houve alteração na vida dos estudantes, decorrente de uma prática interdisciplinar: eles percebem a globalidade do conhecimento; mudam de atitude; melhoram os hábitos; ampliam a consciência crítica, para além de uma disciplina, e não resistem ao trabalho 
interdisciplinar, salvo exceções. Isso marca a relevância de uma prática pedagógica interdisciplinar, porque altera o modo de ver do estudante e, sem dúvida, do/a próprio/a professor/a.

Destaca-se que todas as narrativas atribuíram à interdisciplinaridade um caráter eminentemente epistemológico, de superação do conhecimento fragmentado, mas sem pensar em suas raízes, na produção capitalista com sua conexão tênue com a produção da ciência, decorrente, entre outros fatores, da ausência de um estudo mais aprofundado e com ênfase na práxis. A importância dada ao epistêmico é algo que pode ser repensado no próprio contexto das práticas pedagógicas, na formação continuada que pode ocorrer nas coordenações e em outros espaços formativos.

A professora Karina, ao explicar que "a interdisciplinaridade é difícil, mas possível, dá certo" e que "ainda não foi contemplada em sua plenitude, é um trabalho difícil", recoloca a questão da complexidade aqui discutida e a necessidade de uma incursão permanente no sentido do devir humano. Em termos concretos, a despeito das contradições presentes nas práticas e concepções, acredita-se ser importante a seguinte metáfora: o faminto e sedento não pode esperar a revolução para comer e beber. A lógica dessa espera sem comida e bebida é a morte iminente. Dessa forma, não se pode esperar pela desarticulação do capital sobre o trabalho, e sua forma opressiva para desencadear um trabalho interdisciplinar. O que se pode fazer, melhor fazer, mas sem perder de vista a necessária busca de articulação epistêmico-ontológica-pedagógica.

Enfim, no âmbito propositivo, defende-se a importância de promover um estudo sistemático de caráter prático-teórico sobre a interdisciplinaridade na Educação de Jovens e Adultos, tendo por base o pensamento freiriano na perspectiva do Círculo de Culturas, educação como práxis; educação problematizadora e libertadora com parcerias de movimentos sociais, grupos de pesquisa e outros movimentos sociais comprometidos com a questão.

\section{REFERÊNCIAS}

CAPRA, Fritjof. O ponto de mutação: a ciência, a sociedade e a cultura emergente. Tradução Álvaro Cabral. São Paulo: Cultrix, 1982.

FAZENDA, Ivani Catarina Arantes. Interdisciplinaridade: história, teoria e pesquisa. 18. ed. Campinas, SP: Papirus, 2012.

FREIRE, Paulo. Pedagogia do oprimido. 59. ed. Rio de Janeiro: Paz \& Terra, 2015.

LÜDKE, Menga; ANDRÉ, Marli E. D. A. Pesquisa em educação: abordagens qualitativas. 2. ed. Rio de Janeiro: EPU, 2015.

MORIN, Edgar. A cabeça bem-feita: repensar a reforma, reformar o pensamento. Tradução Eloá Jacobina. 19. ed. Rio de Janeiro: Bertrand Brasil, 2011.

PASCAL, Blaise. Pensamentos. Tradução e notas Paulo M. Oliveira. Bauru, SP: Edipro, 1995.

PINTO, Álvaro Vieira. Sete lições sobre educação de adultos. São Paulo: Cortez, 1982.

TONET, Ivo. Interdisciplinaridade, formação humana e emancipação humana. Serv. Soc. Soc., São Paulo, n. 116, p. 725-742, out./dez. 2013. 